Palimpsesto Vol. 11, No 19 (Julio-diciembre, 2021): 76-102

Universidad de Santiago de Chile, ISSN 0718-5898

\author{
Néstor Nicolás Arrúa \\ Universidad Nacional de La Plata \\ nnarrua@gmail.com
}

\title{
Paulo Freire y los trabajadores sociales argentinos. La temprana recepción intelectual del pedagogo brasileño en las revistas profesionales del trabajo social, 1969-1973*
}

\author{
Paulo Freire and the Argentine social workers. The early intellectual \\ reception of the Brazilian Pedagogue in the Social Work's professional \\ reviews, $1969-1973$
}

\section{Resumen}

Este trabajo es un avance del proceso de investigación sobre la recepción intelectual de la obra escrita de Paulo Freire en las revistas profesionales del Trabajo Social argentino entre los años 1969 y 1973. La trayectoria vital del pedagogo brasileño Paulo Freire es un dato esencial a las condiciones de producción y difusión de sus ideas e incluso de su recepción en el campo del trabajo social argentino. El congreso de Servicio Social en Santiago de Chile del año 1969 fue el punto álgido de la relación entre las ideas educativas de Freire en el campo profesional y la política radicalizada de las organizaciones de la nueva izquierda conosureña. Los viajes del intelectual brasileño a la Argentina, y los intercambios mediante seminarios y congresos internacionales fueron los vehículos de la circulación de las ideas pedagógicas, en las cuales las categorías de 'concientización', 'praxis' y 'liberación' se introducen en una trama de lecturas y lectores católicos y populistas en proceso de radicalización política. Indagamos la difusión del

* El siguiente artículo se enmarca en los Proyectos de Investigación: "Para una historia de los intelectuales argentinos y latinoamericanos del siglo XX. Un estudio de las revistas y publicaciones editadas por agrupamientos culturales, universitarios y políticos (1917-1990)", dirigido por el Dr. Adrián Celentano (FaHCE-UNLP); y el Proyecto de Investigación: "Las escuelas y la participación de las mujeres migrantes. Representaciones de los educadores y de las líderes migrantes participantes de la vida de las escuelas de la ciudad de La Plata y gran La Plata", dirigido por el Dr. Diego Bermeo (FTS-UNLP). Agradezco los comentarios a versiones previas de este artículo a Adrián Celentano, Diego Bermeo, Carolina Mamblona, Francisco O. Toto y Alejandra Parkansky, junto a los pares revisores ciegos. 
pensamiento freireano en las revistas profesionales (Hoy en el Trabajo Social - Selecciones del Servicio Social), identificamos los intelectuales que leen la obra del pedagogo brasileño y analizamos las apropiaciones en una trama de sentido. Este trabajo se detiene en la instrumentalización de las ideas freireanas en el debate intelectual del Trabajo Social en las revistas profesionales para realizar un aporte en el conocimiento de la historia de la disciplina en nuestro país.

Palabras claves: Trabajo Social, Freire, Nueva Izquierda, Intelectuales.

\begin{abstract}
This work is an advance of the research process on the intellectual reception of the written work of Paulo Freire in the professional reviews of the Argentine Social Work between the years 1969 and 1973. The vital trajectory of the Brazilian pedagogue Paulo Freire is an essential data to the conditions of production and dissemination of his ideas and even of their reception in the field of Argentine social work. The 1969 Social Service Congress in Santiago de Chile was the high point of the relationship between Freire's educational ideas in the professional field and the radicalized politics of the organizations of the Latin America's new left. The trips of the Brazilian intellectual to Argentina, and the exchanges through international seminars and congresses were the vehicles for the circulation of pedagogical ideas, in which the categories of 'conscientization', 'praxis' and 'liberation' are introduced in a mixture of Catholic and populist readings and readers in the process of political radicalization. We investigate the dissemination of Freirean thought in professional reviews Hoy en el Servicio Social and Selecciones del Servicio Social, identify the intellectuals who read the work of the Brazilian pedagogue, and analyze the appropriations in a web of meaning. This work stops on the instrumentalization of Freirean ideas in the intellectual debate of Social Work in professional reviews to contribute to the knowledge of the history of the discipline in our country.
\end{abstract}

Keywords: Social Work, Freire, New Left, Intellectuals.

\title{
Introducción
}

El golpe militar de junio de 1966 comandado por el Gral. Juan Carlos Onganía se propuso reconducir bajo principios autoritarios y nacionalistas el proceso de modernización capitalista de corte desarrollista con una fuerte incidencia del capital extranjero. La "Revolución Argentina" a través de la clausura de los partidos políticos y el parlamento pretendió suspender la vida política ante una situación de creciente inestabilidad económica y política del país. ${ }^{1}$ Este intento se demostró fallido a instancias de la creciente combatividad de sindicatos clasistas e independientes del movimiento obrero en alianza con el movimiento estudiantil radicalizado expresados en el

${ }^{1}$ Remitimos al lector que desee profundizar respecto al período de la "Revolución Argentina" a los siguientes trabajos clásicos: Portantiero, J.C. (1989); Cavarozzi, M. (1997); O’Donnell, G. (1996). 
"Cordobazo" y los levantamientos populares -"puebladas"- en el ocaso de la década. Las Fuerzas Armadas y los partidos políticos mayoritarios a través del Gran Acuerdo Nacional (1972) buscaron retomar el cauce institucional de la vida política jaqueado por la vía insurreccionalista y armada de las organizaciones de la nueva izquierda que crecían en su capacidad de concitar consensos y movilización de masas. ${ }^{2}$

La intervención de la dictadura de Onganía a las universidades nacionales produjo la clausura del clima intelectual de innovación y modernización cultural iniciado en los años desarrollistas. Asimismo, el movimiento estudiantil asume inicialmente un papel protagónico en la defensa del cogobierno, contra los exámenes de ingreso y los cupos (el llamado "limitacionismo"), así como también la lucha por los comedores estudiantiles ante la expansión de la matricula estudiantil que se advierte en los años 1960 (Buchbinder, 2005, pp. 191-214). A fines de la década la escena política universitaria tuvo un desplazamiento de las organizaciones estudiantiles reformistas de la izquierda comunista, socialista y del humanismo cristiano hacia el protagonismo creciente de organizaciones maoístas, peronistas y de otras tendencias radicalizadas.

A pesar de la clausura de la vida política y la intervención a las universidades, el debate político cultural continuó en espacios no institucionales, en circuitos alternos donde se cruzaban estudiantes, trabajadores y barriadas populares. Asimismo, se llevaba a cabo la edición masiva de folletos, revistas y libros publicados por diversas editoriales de divulgación de las corrientes de la nueva izquierda, por ejemplo, Galerna, Juan Alvarez, Tiempo Contemporáneo, Centro Editor de América Latina o la editorial Siglo XXI.

En este sentido, el trabajo se propone demostrar que la temprana recepción intelectual de Paulo Freire se articula con un proceso de politización de los trabajadores sociales a través de un circuito de debates y ediciones que une Chile, Uruguay y Argentina. Asumiendo esta hipótesis, las lecturas de Freire estuvieron sobredeterminadas por la política en la coyuntura histórica de 1969 a 1973. Para dar cuenta de ello realizaremos un rastreo de lecturas y debates sobre los primeros textos de Freire en las revistas profesionales argentinas Hoy en el Servicio Social y Selecciones del Servicio Social. Las diversas tendencias ideológicas que elaboraron una crítica a la neutralidad política del profesional en relación a los escritos del pedagogo brasileño tuvieron un apogeo en los primeros años de la década de 1970. Con el triunfo del tercer gobierno peronista se consagra la llegada de colectivos políticos e intelectuales de la nueva izquierda, lectores clandestinos de la obra freireana, al diseño de ciertas políticas sociales del gobierno en relación a la educación de adultos. En tanto, significa también un punto de llegada de un proceso de recepción de los textos freireanos en las revistas de trabajo social con un carácter tenso y contradictorio en torno a la significación de la obra del pedagogo brasileño.

\section{Revistas profesionales, intelectuales y circulación de ideas}

La historia intelectual nos permite analizar los procesos materiales de circulación de las ideas en diversos soportes para establecer circuitos de intercambio, comprender las formas de intervención intelectual, su tipología y figuras intelectuales dominantes en cada coyuntura histórica.

${ }^{2}$ Respecto a la nueva izquierda consideramos fundamental el texto Tortti, M. C. (1999) y el Tortti, M.C.; Celentano, A. Chama, M. (2014). 
La circulación de ideas tiene un soporte material en los textos publicados en diversos formatos -libros, revistas, folletos, apuntes, programas de estudio-, esta materialidad introduce un conjunto de actores menos visibles pero necesarios -editores, difusores, imprenteros, correctorespara reconstruir la trama de sentidos de las configuraciones ideológicas (Karsz, 2007, pp. 50-51). Dado que la práctica intelectual no es una actividad individual sino colectiva de los individuos que tienen la función de intelectuales (Gramsci, 1975, pp. 14) e intervienen en la esfera pública según normas y valores históricos bajo condiciones económicas, sociales y políticas no elegidas. Si acordamos como manifiesta Bourdieu (2007) que "los textos circulan sin su contexto" (p. 161), le agregamos, sin su contexto "de producción". A partir de esto, el autor galo sostiene que se presenta una lógica de malentendido estructural debido a la autonomización del texto respecto de las condiciones de producción y difusión del mismo. Por lo cual, nos remitimos a los estudios de recepción intelectual que se inspiran en el esquema del proceso de trabajo de Karl Marx. El momento de producción, difusión, recepción y apropiación (Tarcus, 2013, pp. 30-32) nos convida a pensar, en nuestro caso la obra de Paulo Freire, y los diversos actores involucrados. Por ello, analizaremos el contexto de producción de los textos de Paulo Freire durante su exilio en Chile y sus principales textos, la labor de difusión de ICIRA, la editorial Tierra Nueva de Uruguay y Siglo XXI en la difusión del pedagogo brasileño a cuál le aportamos la intervención de la editorial ECRO. Posteriormente, daremos pasos concretos en el estudio de la recepción de los textos de Freire entre los trabajadores sociales argentinos a través de las revistas profesionales, y las lecturas que desarrollan produciendo apropiaciones específicas en la coyuntura histórica de los años 1969 a 1973.

En la coyuntura de fines de los años 1960 y principios de la década siguiente se entrecruzan distintas tipologías del intelectual: por un lado, la figura del compromiso político, tan cara a las ideas y posiciones de Jean Paul Sartre, donde el escritor no subordinaba la autonomía de su campo a la intervención política, sino que era parte integral de la misma; por otro lado, la figura del intelectual revolucionario quién está dispuesto a sacrificar dicha autonomía. En este período la figura del experto emergió en relación a la modernización desarrollista del Estado y/o empresas capitalistas que convocaba a intelectuales para el asesoramiento, diseño y ejecución de proyectos en base a sus saberes específicos. En este caso, la subordinación al poder del Estado por el intelectual implica la disposición de sus conocimientos y prácticas en aras de una supuesta neutralidad ideológica (Traverso, 2014, pp. 40-47). La figura del profesional especializado experto- en el desarrollo de la comunidad, con una formación centrada en la corriente norteamericana del Social Work, que proclamaba una neutralidad política con el objetivo de aplicación aséptica de métodos de intervención fue discutida por diversos colectivos profesionales en los años sesenta.

Consideramos las revistas como un "canal de expresión" (Bauman, 1997) de un agrupamiento cultural (Gramsci, 1975, p. 143). La revista es una práctica intelectual que tiene variaciones en distintas coyunturas históricas y tipologías. En nuestro caso analizaremos revistas profesionales que pretenden intervenir sobre el campo intelectual del trabajo social, e incluso, incidir sobre las políticas sociales de los Estados de Bienestar. Las revistas están pensadas, según Sarlo (1992) para la "escucha contemporánea". Las decisiones tomadas en su diseño, orden interno y los procesos de modernización cultural constituyen la intervención coyuntural de la revista que son precisos reconstruir por los especialistas.

En el campo de las revistas profesionales del Trabajo Social a fines de los años sesenta dominaba la escena intelectual dos publicaciones periódicas: la revista Selecciones del Servicio Social y Hoy en el Servicio Social. En principio, consideramos la revista Hoy en el Servicio 
Social (en adelante: Hoy) como una revista de la nueva izquierda intelectual ya que busca dar una batalla política en el campo intelectual del Trabajo Social, establece alianzas con otros colectivos culturales al mismo tiempo que plantea una ruptura generacional con posiciones ideológicas ligadas a un compromiso político radicalizado (Arrúa, 2019; Terán, 2009). Esta publicación se edita desde el año 1965 hasta su cierre por la persecución al colectivo editor por la última dictadura militar en 1977. El colectivo que edita la revista estaba compuesto por jóvenes egresados y docentes del Instituto de Servicio Social, tales como Juan Barreix, Alberto Dufour y Luis Fernández. Dicha institución fue creada por el gobierno desarrollista de Arturo Frondizi a instancias de las recomendaciones sugeridas por la experta Valentina Maidagán de Ugarte (Alayón, 1992, p. 123). El carácter voluntarista e independiente de la revista se desprende del sello editor en su primera etapa "Barreix-Carrasco\&Cía", con la emergencia de una política de edición de libros que determinará la aparición definitiva del sello "ECRO" en referencia al Esquema Conceptual, Referencial y Operativo elaborado por el afamado psiquiatra y psicoanalista Enrique Pichón-Rivière con el cual el colectivo cultural referenciaba su propuesta teórica e ideológica.

El principal objetivo que persigue su grupo editor será la oposición ideológica al apoliticismo o neutralidad valorativa de los agentes respecto de las políticas gubernamentales. La batalla para la revista Hoy es de ideas y es política. Con dicho propósito construye una red de distribución de sus publicaciones y sus miembros participan en seminarios y jornadas actuando como un partido [político] profesional. Esta primera etapa caracterizada por el compromiso del profesional contra el asistencialismo y por la profesionalización del Trabajo Social.

La revista Selecciones del Social Work aparece bajo el sello de la editorial Humanitas, su primer número sale en 1967 hasta el año 1978, dirigida por Aníbal Villaverde (pedagogo, escritor y editor), junto a la asistente social Sela Sierra con una estricta periodicidad cuatrimestral. La editorial había comenzado en 1963 a publicar la colección "Cuadernos de Asistencia Social" dirigida por la anteriormente mencionada profesional en una vasta lista de autores y temas referidos a la actualización temática y conceptual de la Asistencia Social.

La revista expresa una corriente modernizadora en diálogo con distintas tendencias del pensamiento cristiano. Se enfocaba en sus inicios a la actualización disciplinar a través de la traducción y difusión de textos norteamericanos de la Nacional Association of Social Work imbuidos en la sociología funcionalista y la reproducción de los lineamientos de la Organización de las Naciones Unidas para el Servicio Social.

En la estructura de la revista se evidencia un giro en el número 9 del año 1970 con el cambio del nombre a Selecciones de Servicio Social (en adelante: Selecciones) y la renovación de la "Redacción" con la inclusión de Natalio Kisnerman y Hernán Kruse. Este cambio a tono con los debates regionales y nacionales indica una vinculación con grupos profesionales latinoamericanos que privilegiaban el desarrollo científico-técnico de la profesión sin adherir o participar de procesos políticos radicalizados.

Las publicaciones se desenvuelven en una suerte de juego de espejos en la cual definen sus posiciones ideológicas, teóricas y profesionales en relación al otro, esta dialéctica tiene incluso un elemento sobredeterminante en la política. Los debates están tensionados en relación a las posiciones divergentes respecto al accionar represivo en las Villas de Emergencia de la dictadura de Onganía y la adhesión a los procesos de insurrección popular y los movimientos estudiantiles del cono sur. Las oposiciones aparecen especialmente en los términos que utilizan para referirse a la profesión -visitadora de higiene, asistente social, trabajador social- con implicancias ideológicas y políticas en cada caso. Por ejemplo: posteriormente al cambio de 
nombre de la revista Selecciones del Social Work a Selecciones del Servicio Social en el año 1970, la revista Hoy en el Servicio Social pasa a intitularse Hoy en el Trabajo Social (año 1971, número 21) al considerar que la denominación "Trabajo Social" invoca una cuestión política (radicalizada) en tanto una forma superadora del "asistencialismo".

\section{Freire en el campo político e intelectual chileno}

En la década de 1960 Chile fue el epicentro de intercambios entre intelectuales de izquierda, militantes políticos y profesionales comprometidos en el cono sur. Las ciencias sociales tuvieron un impulso decisivo con la conformación de un núcleo de intelectuales de la Comisión Económica para América Latina (CEPAL) bajo la impronta de Raúl Prebisch, y los espacios de investigación en las instituciones universitarias, tales como la Universidad de Chile y la Pontificia Universidad Católica de Santiago. Estas últimas constituyeron dos reconocidos centros de estudio, edición e investigación conocidos como el CESO (Centro de Estudios SocioEconómicos) y el CEREN (Centro de Estudios de la Realidad Nacional), en los cuales se llevaron a cabo importantes iniciativas editoriales, tal como la revista Chile hoy -abordada en el dossier por Laura Briceño Ramírez. El tópico que concentraba los debates de los cientistas sociales era el carácter del desarrollo a partir de la 'teoría de la dependencia' en un país periférico; un debate atravesado asimismo por el clivaje ideológico gradualismo/revolución que atravesó a los agrupamientos intelectuales y políticos de la nueva izquierda cono sureña. La 'transición al socialismo' en tiempos de los gobiernos del democristiano Frei Montalva, y luego, el socialista Salvador Allende impregnó la segunda mitad de los años sesenta para cobrar mayor vigor durante el intenso periodo de los años setenta hasta el golpe de Estado en 1973.

La figura predominante del intelectual revolucionario cuestionó las bases de la neutralidad política que cultivaba el experto en una coyuntura de efervescencia política en el país trasandino. Dicha figura parte del emplazamiento de ciertos intelectuales de izquierda en centros de investigación ligados a las universidades, en las cuales gozaban de cierta autonomía y financiamiento del Estado al mismo tiempo que estaban en relación con organizaciones políticas desde abajo manifestando su compromiso (Moyano Barahona; Loyoza, 2019, p. 206).

Los sectores medios juveniles protagonizaron un ciclo de movilización y cuestionamiento a las universidades, especialmente, en el reclamo de cogobierno y acceso masivo a las instituciones educativas superiores. Bajo el lema "universidad para todos", en el año 1969, diversos colectivos estudiantiles de izquierda -Juventudes Comunistas, Juventud Socialista, miristas y radicales-, conformaron alianzas para enfrentar a los sectores democristianos que se encontraban al borde de una ruptura interna. La aparición del Movimiento de Acción Popular Unitaria (MAPU) y la creación de la alianza de las izquierdas -Unidad Popular-, consolidó la renovación de las autoridades universitarias y las demandas estudiantiles de cogobierno.

Chile se erigió en los años sesenta en un polo de atracción para un vasto arco de intelectuales y militantes de izquierda exiliados de las dictaduras militares y políticas represivas de sus respectivos países de origen. Para muchos de ellos que provenían de organizaciones guerrilleras (Brasil, Uruguay, Argentina y Bolivia), el exilio se convertía en un tiempo/espacio para la resistencia y denuncia de la represión en su propio país en la medida que se producían nuevos intercambios teóricos y políticos entre cuyos temas sobresalía el riesgo de una posible "desviación militar" (Marchesi, 2019, p. 109). Desde Brasil, un conjunto de académicos ligados a 
la teoría de la dependencia del CEBRAP (Centro Brasileiro de Análise e Planejamento) huyendo de la represión de la dictadura militar se instalan en Chile, e incluso participan activamente del CESO (Theotônio Dos Santos, André Gunder Frank, y posteriormente, Ruy Mauro Marini). En el campo del trabajo social, el joven trabajador social Vicente de Paula Faleiros, dirigente de $A c ̧ a ̃ o$ Popular, se inserta en la Universidad de Valparaíso y desarrolla una importante labor intelectual (Arrúa, 2017).

El pedagogo brasileño Paulo Freire se exilia en Santiago desde fines de 1964 hasta abril de 1969, allí toma contacto con grupos de la democracia cristiana y continúa su trabajo intelectual hasta la publicación del libro que lo consagrará: Pedagogía del oprimido. Freire había lanzado en Recife (Brasil) el Movimiento de Cultura Popular, una iniciativa de alfabetización de adultos que fomentaba un encuentro del intelectual con el "pueblo". La iglesia y las organizaciones cristianas como la Juventud Universitaria Católica y la Acción Católica tenían un rol destacado, muchos de sus miembros de sectores medios, llevó adelante el Movimiento de Educación de Base. Desde el pensamiento católico Paulo Freire participaba de los debates ideológicos en torno al nacionalismo y el desarrollo del Brasil a partir de su propuesta de educación popular. Si bien se evidenciaban las influencias de Jacques Maritain, Emmanuel Mournier, Karl Mannheim o el esloveno Zevedei Barbu, Freire retoma los temas del ISEB (Instituto Superior de Estudos Brasileros). En este instituto predominaban las tendencias nacionalistas y lecturas fenomenológicas sobre la "autenticidad" y la unidad nacional, por ejemplo, en los trabajos de Hélio Jaguaribe, Freire repone la reflexión sobre los niveles de consciencia y la concientización dentro de una relación elite-masas (Pécaut, 1990, p. 167). En este sentido, plantea un vínculo entre una elite "auténtica" concentrada en los intereses nacionales y las masas en un proyecto popular de desarrollo y liberación que termine con la alienación del hombre. Los tópicos de la concientización, la alienación y la autenticidad del hombre poseen una concepción filosófica humanista e historicista.

Esta variante historicista deposita en la "praxis" el peso de innumerables "mediaciones", además hace de la ciencia una superestructura y del presente un corte de esencia de la contemporaneidad (Althusser, 2010, pp. 144-148). Sin dudas, la propuesta teórica freireana se entronca con los textos juveniles no publicados por Karl Marx, lo cual ha propiciado un dialogo con las tendencias humanistas de diversas corrientes ideológicas.

Asimismo, aparece en Freire una insistencia en la democratización inmediata de las relaciones sociales con un énfasis en la esfera comunitaria, por lo cual, se evidencia una desconfianza con todo lo que proviene del "asistencialismo" (Pécaut, 1990, p. 168). En este sentido, Freire elabora su propuesta educadora en contacto con los trabajadores sociales de Brasil siendo invitado a conferencias del Servicio Social en el nordeste brasileño o en su ámbito laboral en el Servicio Social de la Industria en Pernambuco (Rodríguez, 2015, pp. 57-58).

A su llegada a Chile en el año 1964 establece lazos con un sector del partido gobernante, específicamente, con el dirigente del Partido Demócrata Cristiano Jacques Chonchol, éste último motivado por el trabajo del pedagogo en comunidades agrarias del nordeste brasileño. Chonchol durante el gobierno de Frei Montalva fue nombrado Vicepresidente del Instituto Nacional de Desarrollo Agropecuario (INDAP) que emprende el proceso de Reforma Agraria auspiciado por la Ley 16.640 que amplía la anterior ley cinco años antes. Este organismo confluye con el Instituto de Capacitación e Investigación en Reforma Agraria (ICIRA) patrocinado por la UNESCO en el cual se insertó laboral e intelectualmente Paulo Freire en 1968.

El partido gobernante atravesaba debates internos en franca disputa con tendencias que asumían la necesidad de una "vía no capitalista de desarrollo". Con el discurrir del año 1969 esta 
tendencia "rupturista" dará paso a la conformación del MAPU cuyos dirigentes principales fueron Jacques Chonchol, Alberto Jeréz, Rafael Agustín Gumucio, Rodrigo Ambrosio, que confluirán con al Partido Socialista y el Partido Comunista en el frente político de izquierda Unidad Popular, con la candidatura del socialista Salvador Allende

En el año 1966 se lanzó la Campaña Nacional de Alfabetización en territorio chileno en donde "el método Freire" iba tomando forma al calor de las experiencias de trabajo educativo con las comunidades rurales de la región metropolitana. Un conjunto de técnicas de alfabetización fueron puestas en juego y sistematizadas en Chile por Freire y su equipo de capacitadores y promotores: el diálogo, papelógrafos, filminas y fichas de ilustraciones (Aranvena Alvarado et al, 2015).

A través de ICIRA Paulo Freire publicó y tradujo gran cantidad de textos que conformarán el corpus teórico de las ideas freireanas asociadas a la alfabetización de adultos en comunidades agrarias centradas en la noción de alienación y liberación de hombre en una corriente humanista e historicista. El término concientización será una palabra clave que se propagará en el periplo chileno para identificar su pensamiento.

\section{Viajes, encuentros y debates. Freire en las revistas de Trabajo Social en Argentina}

Analizaremos la recepción intelectual de las ideas de Paulo Freire a partir de los viajes e intercambios de los trabajadores sociales en el cono sur, específicamente, entre Argentina, Chile y Uruguay, sus lecturas en las revistas profesionales de la Argentina en una coyuntura histórica signada por apuestas políticas e ideológicas radicalizadas.

El 4to. Seminario Regional Latinoamericano de Servicio Social realizado en Chile fue el epicentro de intercambios entre intelectuales del campo del trabajo social que nos permitirá comprender el proceso de recepción de Paulo Freire por parte de los trabajadores sociales argentinos. La misma tiene diversas aristas: primero, la recepción intelectual de Paulo Freire está determinada por la política. El pedagogo brasileño es leído y sus textos llegan a manos de los trabajadores sociales argentinos a través de viajes a Chile en el cual observan el proceso chileno de politización y debates ideológicos. Por ello, el contexto chileno de reforma universitaria de los planes de estudio en las Escuelas de Servicio Social ha concitado el interés del grupo ECRO, dado que integra los avances teóricos de las ciencias sociales y el compromiso social. El país vecino encaró el proceso de reformas curriculares en una alianza entre el movimiento estudiantil e intelectuales vinculados a centros de investigación y docencia. Entonces, el método freireano de concientización se articuló a la búsqueda de una alianza entre el movimiento estudiantil y el grupo ECRO en las carreras de Servicio Social sólo logrado en el marco de las intervenciones universitarias del tercer gobierno peronista.

Segundo: Freire se convirtió en objeto de disputas en un juego de espejos por parte de las revistas Hoy y Selecciones, ambas expresaban tendencias ideológicas divergentes en el campo intelectual del trabajo social argentino. El combate por una profesión comprometida social y políticamente determinó la emergencia en el campo de la revista Hoy y se articuló con la propuesta de un armazón teórico propio del Servicio Social. La revista Selecciones surgió con un proyecto editorial concentrado en la divulgación de la corriente norteamericana, con una posición de modernización conservadora. Esta asumió recién en el año 1970 una perspectiva latinoamericana con un giro en su organización y composición. 
Podríamos afirmar incluso que esta tensión y querella en torno a Freire se manifestó ya entre los integrantes mismos de la delegación argentina al seminario, cuestión que abordaremos a continuación.

\section{Chile, 1969}

El 4to. Seminario Regional Latinoamericano de Servicio Social fue auspiciado por el Departamento de Servicio Social de la Universidad de Concepción (Chile) entre el 27 de enero al 2 de febrero de 1969. Una nutrida concurrencia de público asistió a las conferencias con una delegación argentina nada desdeñable: se encontraban allí Natalio Kisnerman, Ezequiel AnderEgg, Juan Barreix y Alberto Dufour (los dos últimos eran editores de la revista Hoy).

En el número 16-17 de abril-mayo del año 1969 la revista Hoy reseñó las actividades y exposiciones del seminario regional en forma pormenorizada a cargo de Alberto Dufour. Los editores decidieron también la publicación de la intervención de Barreix en formato de artículo en dicho número, mientras que en el número 21 de la revista del año 1971 -dos años después del viaje a Chile- publicaron las intervenciones de Ricardo Hill, Ornela Flores y Manuel Rodríguez Rodríguez junto a las conclusiones del seminario.

En un escenario de intensos debates políticos generados ante la gran expectativa en los sectores radicalizados de la universidad debido a la alianza entre el Partido Comunista, el Partido Socialista y el MAPU. En la Universidad de Concepción existía un importante desarrollo de las fuerzas miristas, este partido decidido a encarar un proceso de confrontación armada a través del desarrollo de una "guerra revolucionaria, irregular y prolongada", se encontraba en tensión con los otros actores de la izquierda chilena encaminados a una "vía pacífica al socialismo". Durante el año 1969 se produce, sin embargo, una escisión en el Movimiento de Izquierda Revolucionaria (MIR), llamada MIR - Frente Revolucionario, esta fracción apoyaba la Unidad Popular, contaba entre sus filas al intelectual marxista Luis Vitale, orador invitado en el seminario de Trabajo Social (González Monarde, 2019).

Las principales casas de estudios superiores de Chile desde 1967 estaban en un proceso de reforma de la vida política que implicaba una creciente demanda estudiantil por la democratización de las instituciones y la modernización de los planes de estudio. En las ciencias sociales, la renovación y actualización académica estuvo acompañada por una agenda política radicalizada que demandaba un perfil profesional de compromiso social. En el Trabajo Social, los debates profesionales y académicos en las Escuelas de Servicio Social de Concepción, Valparaíso y Santiago se producían alianzas con los centros de investigación de las ciencias sociales, en especial, con los estudios dependentistas y la sociología de la comunicación de Armand Mattelart (Illanes, 2009, p. 64). La trabajadora social Eliana Moreau de Young (Valparaíso) planteaba la necesidad de integrar al trabajo social a las ciencias sociales bajo nuevos parámetros de cientificidad en consonancia con postulados althusserianos e integrando los estudios comunicacionales con la metodología de la concientización de Paulo Freire para la realización de talleres en el mundo obrero y popular (Moreau de Young, 1972). Los estudios dependentistas, las teorías reproductivistas y la concientización freireana se combinaban en busca de un efecto ideológico radicalizado en una coyuntura política atravesada por la expectativa generada con la Unidad Popular. 
En la Universidad de Concepción, el movimiento estudiantil conducido por miristas y socialistas avanza en la reforma de la casa de estudios con la demanda de libertad académica, una evaluación permanente, seminarios y actividades educativas, según aparece en un texto anónimo en la revista de crítica cultural argentina Los Libros (Anónimo, 1971, pp. 14-16). En la carrera de Servicio Social resulta convocado en 1968 para ejercer su dirección el trabajador social uruguayo Hernán Kruse, asiduo colaborador del grupo ECRO y figura destacada del campo intelectual latinoamericano del trabajo social.

El 4to Seminario regional se organizó, según Dufour, en distintos ejes: 1. La alienación y praxis del Servicio Social; 2. Nuevos instrumentos del Servicio Social; 3. Nuevas ideas para el marco de referencia conceptual del Servicio Social; 4. El Servicio Social en Prospectiva (Dufour, 1969, pp. 51-70).

En el eje 1, Juan Barreix expuso una conferencia titulada "Alienación de los profesionales de Servicio Social en los contextos en transición en América Latina", publicado íntegramente por la revista, y luego, Natalio Kisnerman, director de la carrera de Servicio Social en Gral. Roca, expuso sobre "Los métodos básicos y su uso en una sociedad sub-desarrollada". Juan Barreix, quien ofició de representante del grupo ECRO en el seminario regional, abordó el tema de la alineación profesional a partir de la problemática del proceso de institucionalización del Servicio Social en un medio social en vías de modernización e industrialización que implica la adopción de esquemas importados. Kisnerman propone que la profesión tenga un rol de generación de conflictos, en el sentido de "insertar al hombre en su realidad para que libere su potencial", y alega que el asistente social tiene un papel de "precipitador" del cambio antes que su agente. Esta posición tiende a plantear reservas respecto de las posiciones desarrollistas que definían al trabajador social como "agente de cambio".

En el eje 2, expuso el reconocido profesional uruguayo Ricardo Hill sobre diagnóstico en el Servicio Social y su compatriota Violeta Tálice sobre la supervisión en la profesión. En el mismo eje, se destaca la exposición de Sergio Villegas, coordinador del programa de alfabetización del ICIRA y militante político que se titula "El método de concientización de Paulo Freyre". Según Dufour, Villegas expuso sobre el método de concientización de Paulo Freire, acentuando su carácter humanista, liberador y la experiencia en comunidades campesinas, analiza el paso de la 'conciencia ingenua' a la 'conciencia crítica'; desarrolla el concepto de diálogo en la pedagogía freireana como praxis con la aplicación de un "universo vocabular" adaptado a la realidad chilena.

En el eje 3 se compone de tres exposiciones sobre conceptos y teorías en el Servicio Social. Alli, Ornela Flores de la Universidad de Chile (Santiago) realiza una exposición titulada "La Cultura de la Pobreza y el Servicio Social". Luego, la exposición de la trabajadora social Nidia Alwyn de Barros "La teología post-conciliar y el Servicio Social", y finalmente, el teórico marxista y militante del MIR-FR Luis Vitale sobre "Marxismo y Servicio Social". El énfasis de Vitale, según Dufour, está puesto en una crítica al Servicio Social en una sociedad de clases y el rol del marxismo como herramienta teórica de crítica al capitalismo para terminar con la alienación. Por lo cual, la temática de la alienación desde una perspectiva marxista y las tendencias radicalizadas del cristianismo tercermundista estaban presentes en el seminario. Sin embargo, resulta interesante que la revista publique la intervención en el número 21 (1971) de la profesional chilena Ornela Flores. Ella utiliza el concepto de "cultura de la pobreza" mediante el estudio del antropólogo Oscar Lewis sobre familias mexicanas para plantear la necesidad de que el Servicio Social esté junto a los pobres para pensar las características de la pobreza. Resulta estimulante revisitar este trabajo a la luz del significado que tuvo la edición del libro de Oscar 
Lewis, Los hijos de Sánchez, por la editorial Fondo de Cultura Económica en 1964 auspiciado por Arnaldo Orfila Reynal. El libro determinó la salida del director de la editorial y se convirtió en un episodio de la 'guerra fría cultural' que configuró la emergencia de una editorial de izquierda, atenta a las innovaciones teóricas, como la editorial Siglo XXI fundada por el propio Orfila Reynal poco tiempo después (Sorá, 2017, pp. 151-168).

En el eje 4, las exposiciones de Seno Cornely, Ezequiel Ander Egg y Manuel Rodríguez Rodríguez cierran el seminario regional. Dufour registra y reseña las primeras dos exposiciones con énfasis en la segunda, en la cual Ander Egg en una exposición titulada "La revolución latinoamericana y el Servicio Social" afirma que América Latina se encuentra en una situación Pre-Revolucionaria y que los trabajadores sociales deben escoger entre "Revolución o Contrarrevolución", y tomar posición ante el clivaje "Status quo vs. liberación del hombre". El intelectual argentino otorga importancia a la función educativa de la profesión en donde también se debe escoger entre "educar para ajustar a la estructura" o "educar para liberar", con referencia a la función concientizadora de la profesión en clara alusión a Freire.

Finalmente, Dufour afirma que las exposiciones de Ezequiel Ander Egg y Manuel Rodríguez Rodríguez fueron las que mayor atención e importancia concitaron en el público en oposición a las exposiciones sobre marxismo y teología de la liberación. Manuel Rodríguez Rodríguez fue un dirigente estudiantil del Partido Socialista, estudiante de Servicio Social y vicepresidente de la Federación de Estudiantes de Chile en Concepción. Dufour aseveraba que el "impacto" causado por la exposición del dirigente estudiantil que "sensibilizó a todos los presentes por la exacta construcción y calidez de lenguaje expresivo" (Dufour, 1969, pp. 68-69). En el número 21 el comité editor de la revista publicará la exposición de Manuel Rodríguez Rodríguez que analizaremos más adelante.

\section{Freire en la revista Hoy}

En la editorial del número 16-17 de la revista el colectivo se vanagloria de ser los introductores de las ideas de Paulo Freire en el trabajo social argentino a través de la publicación de una conferencia del pedagogo brasileño. Consideran que la elaboración de la metodología de la concientización se incorporará al acervo de los métodos e instrumentos propios del Servicio Social, una tarea compartida con colegas uruguayos y chilenos.

La editorial manifiesta que "Sus experiencias, realizadas principalmente en el área de la alfabetización de adultos y a través de una "pedagogía del oprimido", como el mismo la llama, nos tentaron una y otra vez a adaptar sus principios filosóficos y técnicas de trabajo a la propia acción y significado del Servicio Social".

La expectativa por la obra Pedagogía del oprimido, aún inédita al momento de la salida de la revista posiciona al grupo editor como un interlocutor privilegiado del pedagogo brasileño al mismo tiempo que su lectura y edición se inserta en los debates del campo intelectual del trabajo social argentino y latinoamericano.

La revista pretende poder convertirse en un canal de difusión de Freire en el trabajo social argentino con la selección de un texto dirigido a los profesionales del campo en un conjunto de intervenciones que se refieren a su pensamiento. Esta forma será retomada en el número 25 de diciembre de 1972 cuando el grupo ECRO le dedique cuatro artículos al pensamiento de Paulo Freire en un contexto de difusión de su obra absolutamente distinto. En el año 1969 la revista 
presenta las ideas de Paulo Freire al trabajo social en forma "oficial", ya que la utilización de fragmentos mimeografiados de sus trabajos y/o de comentaristas circulaban escapando a la censura en las carreras de Servicio Social de Argentina (Dufour, 1969ª p. 4). En el año 1972, la revista se replantea el pensamiento de Paulo Freire a la luz de la circulación masiva de sus textos y del lugar a la moda que goza el autor.

El texto de Freire es el anteúltimo artículo del número 16-17 de la revista antecedido por un artículo del asiduo colaborador, el trabajador social uruguayo Hernan Kruse, con una colaboración titulada "El Servicio Social en la encrucijada". Allí, Kruse reflexiona sobre el papel decisivo del grupo ECRO en el proceso de reconceptualización en ciernes, en ruptura con la corriente norteamericana que cristalizo los métodos de "Caso, Grupo y Comunidad" que estaban siendo cuestionados en el cono sur. Esta intervención cobra una gran importancia teniendo en cuenta que ejercía la dirección de la carrera de Servicio Social en la Universidad de Concepción a partir de 1968. Le sigue un artículo de Raquel Cortinas de Vidal sobre "El Servicio Social en los países socialistas", un examen de la profesión a través de un viaje de estudios a los países de Europa del este. Asimismo, un texto de Norberto Alayón titulado "Servicio Social de hoy" que plantea un programa de tareas en el campo profesional ligado a la lucha por la ley de reglamentación de la profesión, la jerarquización universitaria de la disciplina y la creación de jornadas de investigación en sintonía con el Documento de Araxá. Posteriormente, la revista sitúa el mencionado texto de Alberto Dufour sobre el 4to. Seminario Regional de Servicio Social, y luego, la publicación de la exposición de Juan Barreix.

Este extenso recorrido del número nos permite comprender la trama de sentido en la cual es introducido el texto de Paulo Freire. O sea, se encuentra enlazada con un conjunto de debates que sitúan al "Servicio Social" en un momento de definiciones políticas, teóricas e ideológicas. La necesidad de dejar atrás una concepción de la profesión ligada al "asistencialismo", al esquema "Caso, Grupo, Comunidad" y la neutralidad operativa del profesional.

La revista publica la conferencia de Paulo Freire que se convertirá en un texto de referencia durante muchos años para el Trabajo Social: "El rol del trabajador social en el proceso de cambio". Bajo este mismo titulo Freire publicó un folleto a través de ICIRA en el año 1968 con el cual se introduce en el debate sobre la "aplicación" de su método en el Trabajo Social. El pedagogo brasileño realiza una crítica de la neutralidad valorativa de los profesionales, y la opción por el "cambio" asociado a la 'humanización' del hombre. Otro aspecto resaltado por Freire será que el trabajador social no es un "agente de cambio", ya que él sólo no puede producir una transformación, sino que propone un término a partir del añadido de una letra: el trabajador social es un "agente del cambio". Esta sutil adición pretende dar cuenta del carácter colectivo del cambio o transformación, en la cual están involucrados todos los hombres. El autor afirma que, "Intentar la concientización de los individuos con quienes trabaja, mientras con quienes también se concientiza, esto y no otro, nos parece que es el rol del trabajador social que optó por el cambio" (Freire, 1969). De esta manera, la concientización que implica el cambio de una perspectiva distorsionada del mundo de los individuos, en el proceso de humanización propuesto el propio profesional también se concientiza.

La atención puesta en el seminario regional por parte del grupo ECRO muestra el punto de inflexión ante los acontecimientos y debates vividos en Concepción. Sin embargo, un acontecimiento externo al seminario generó un quiebre interno y comenzaron a diferenciar sus posiciones políticas e ideológicas dentro del campo intelectual del trabajo social. Nos referimos a la acusación de Marta Escurra, Secretaria Latinoamericana y Vice Presidenta de la Unión Católica Internacional de Servicio Social (UCISS), al grupo ECRO como "cabeza de puente del 
comunismo". La acusación se debe a la vinculación establecida y consolidada entre el movimiento estudiantil y los organizadores del seminario con el grupo ECRO y las distancias asumidas con las posiciones políticas de la organización católica. Esta situación particular fue abordada por la revista Hoy en el Servicio Social mediante una apostilla del número 16-17 en la cual se encarga de responder a las acusaciones para demostrar la falsedad de los dichos de Ezcurra. Desde posiciones ligadas al cristianismo posconciliar y de la Teología de la Liberación, por parte de Oscar Toto y Carlos Eroles o repudiando los dichos de Marta Ezcurra en aras de presentar a la revista Hoy como abierta y plural, en cualquier caso, la herida quedaría abierta

\section{Freire disputado}

Durante el año 1971 Juan Barreix, Ethel Cassineri y Norberto Alayón editaron un libro que compila sus artículos más recientes publicados en la revista Hoy, titulado $A B C$ del trabajo social latinoamericano en manos del propio sello editorial. El grupo ECRO se encontraba en plena disputa por el acceso a espacios de formación profesional, tal como sucedía en la Universidad del Nordeste (Misiones), en donde Barreix ejerció interinamente la dirección de la carrera. Además, mantenía una actividad constante de intervención en las jornadas profesionales nacionales y regionales en las cuales utilizaba su política editorial con una explicita voluntad de enfrentar al "asistencialismo" y las tendencias de la modernización conservadora que participan de la política social del Onganíato. Se destaca la participación en el año 1970 en el 5to. Seminario regional de Servicio Social en Cochabamba (Bolivia) en el momento que gobernaba el Gral. Juan José Torres, militar que representaba una izquierda nacional hasta su derrocamiento a fines de 1971 por el Gral. Hugo Banzer.

La divulgación del libro en las jornadas nacionales, seminarios y congresos internacionales se retroalimentaba con la aparición de publicidades en la revista Hoy desde el número 19-20 (Enero/marzo de 1971) hasta el número 28 (mayo de 1974).

Entre los artículos compilados en el libro se encuentra el trabajo de Juan Barreix titulado "Que es el ECRO", que tuvo dos entregas en los números 12 (1967) y 13/14 (1968). En el libro del año 1971 se introdujeron dos referencias al pensamiento de Freire en los párrafos que definen a ECRO modificando las citas textuales originales de Enrique Pichón-Rivière. La relación establecida entre la propuesta de Pichón-Rivière y las tesis de Freire se asociaban a una postura ética de "trabajo junto al hombre", un posicionamiento ético y político del profesional con los individuos.

La operación intelectual sobre su propio texto da cuenta de la importancia que asumía la lectura de Freire por parte de Barreix en los debates profesionales del trabajo social. En el apartado que atiende el significado de la sigla ECRO, Barreix cita al fundador de la psicología social en Argentina cuando afirma que:

Si me preguntaran a qué vienen aquí, yo les contestaría que ustedes vienen a comprar un aparato que se llama E.C.R.O., dentro del cual está incluido y comprometido cada uno de los operadores, con su estilo personal. Quiero decir que lo que aquí enseñamos y que constituye el núcleo básico, son universales. Nosotros enseñamos a pensar en términos psicosociales, lo que quiere decir que frente a una situación determinada, lo aprendido sirve para plantearse, en el campo mismo de la tarea, las posibilidades o hipótesis del 
acontecer subyacente que la comunidad, el grupo o el sujeto nos plantean. En la medida en que podamos hacer consciente esa fantasía (el contenido subyacente que está implícito, pero no explícito), esa es nuestra tarea", a lo que nosotros podríamos agregar que estaríamos haciendo una labor de CONCIENTIZACIÓN en los términos psicosociales del método de Pablo Freire. (Alayón et all, 1971, p. 167)

Reproducimos el texto con la intervención de 1971 en negrita en el cual se observa la operación que articula el pensamiento de Pichón-Rivière con Freire en la búsqueda de un efecto. Resulta interesante observar que, en aras de pensar un nuevo instrumental y métodos para el Servicio Social, el grupo ECRO se desplaza primero hacia la psicología social, y luego, articula su propuesta con la pedagógica critica de Freire. Esta operación es realizada sobre el texto mismo que explica el significado de ECRO.

En el libro $A B C$ del trabajo social latinoamericano resulta extensamente citado Paulo Freire por Ethel Cassineri en un texto producido para el libro titulado "El trabajo social como disciplina universitaria". La autora utiliza numerosas referencias a Freire para pensar la participación y la humanización de los sujetos en el proceso de cambio.

El grupo ECRO con el número 21 comienza un nuevo nombre para la revista: Hoy en el Trabajo Social; en el número 22 este cambio se expresa en la estética de la portada. De las sobrias tapas de colores uniformes con el logo de figuras de papel en ronda en alusión a ECRO y el nombre de la revista se pasa un diseño con imágenes o patchwork de recortes de periódicos que muestran la urgencia de los acontecimientos. El numero 21 posee una importancia destacada en la trayectoria de la revista, en especial también porque regulariza la salida de los números que estaban siendo espaciados o en números dobles.

En el número 21 de Julio de 1971 los editores de la revista deciden publicar las intervenciones de Ricardo Hill (asistente social uruguayo), Manuel Rodríguez Rodríguez y las conclusiones del IV Seminario Regional de Concepción en 1969.

El artículo de Manuel Rodríguez Rodríguez "La rebelión estudiantil y el Servicio Social" aborda la temática de la juventud y la universidad y las teorías acerca de su rol revolucionario en una etapa signada por su protagonismo. Las extensas referencias al movimiento reformista de Córdoba en 1918 y las rebeliones estudiantiles en Europa en 1968 le permiten justificar el carácter central que juega la juventud en el proceso chileno. En su carácter de dirigente estudiantil afirma que los estudiantes e intelectuales si bien no son una clase social sino un estamento pueden ser actores de la revolución. Este estudiante de la carrera de Servicio Social en la Universidad de Concepción brega por la consolidación de un trabajo social comprometido con el pueblo mediante la conformación de una alianza entre "estudiantes y obreros" que vincule al profesional con el pueblo a través de la "concientización" (Rodríguez Rodríguez, 1971, p. 31).

En el mismo número de la revista se publican las conclusiones del seminario de Concepción dos años después, dado que le permitieron al grupo ECRO justificar su posición en la adopción del término "Trabajo Social", en detrimento de la clásica denominación "Servicio Social", que fuera defendida tan sólo tres números atrás. ¿Por qué se produce este cambio de posición en la denominación de la profesión?

En el año 1970 el número 9 la revista Selecciones del Social Work pasa a llamarse Selecciones del Servicio Social. La 'latinoamericanización' de la revista se observa en el reemplazo del primer bloque de artículos traducidos de autores norteamericanos por referentes latinoamericanos de la profesión. Este cambio estuvo acompañado por la incorporación a la organización de la revista de dos figuras destacadas: Natalio Kisnerman y Hernán Kruse. Este 
giro en la estructura del Comité de Redacción de la revista conformado por Sela B. Sierra, Rosa Perla Resnick, Hernan Kruse y Natalio Kisnerman, este último, trabajador social radicado en Gral. Roca (Río Negro), donde claramente logra establecer una relación de su labor editorial en la revista con su labor docente e incluso en el entramado de la reforma curricular de la Escuela de Trabajo Social de la Universidad del Comahue.

Natalio Kisnerman, Hernán Kruse y Sela Sierra comparten una formación cristiana, con una perspectiva humanista de la profesión que tiende pensar en el rol de acompañamiento del sujeto en un mundo en transformación. Estos comparten la crítica al axioma desarrollista del profesional como "agente de cambio". Sin embargo, Kruse y Kisnerman a diferencia de Sierra han participado activamente en congresos y seminarios sobre la necesidad de la sistematización de los métodos del Servicio Social y la ruptura con la metodología básica del Caso/Grupo/Comunidad de herencia norteamericana. El primero era especialista en el desarrollo de la comunidad en Uruguay, el segundo experto en la metodología de grupos. Incluso ambos fueron asiduos colaboradores de la revista Hoy; el dato curioso es que Hernán Kruse continuó publicando allí al mismo tiempo que formaba parte de la revista Selecciones.

Natalio Kisnerman había participado del 4to. Seminario regional en Concepción, mientras era funcionario de la gobernación de Rio Negro en tiempos de la dictadura de Onganía, a cargo de la Sub-Secretaría de Acción Social que se encargaba de área de Desarrollo de la Comunidad. Esta cuestión fue señalada por el grupo ECRO que denunciaba la colaboración de muchos profesionales con la erradicación violenta de villas miseria por el gobierno militar (AA.VV., 1969, p. 4; Alayón et all, 1971).

En el número 16 del año 1972, la revista Selecciones publica el artículo "El proceso de Concientización de Paulo Freire y su aplicación al Servicio Social” de Natalio Kisnerman, Maria G. de Malvino, Luisa A. de Kisnerman y Domingo Chirico. Para los autores el proceso de concientización y su aplicación al Servicio Social "viene a llenar, sin dudas, una sentida necesidad en todo el ambiente profesional latinoamericano". Realizan una descripción en clave metodológica de los presupuestos teóricos del pensamiento de Freire a partir de distintos términos: Dialogo, Humanización, Conciencia -mágica, ingenua, fanática y critica. El Servicio Social entonces debe desterrar la imagen del donante, y ser un agente de la transformación: "se inserta críticamente en la realidad para objetivarla y actuar sobre ella". La praxis es definida como "acción más reflexión", esto se debe a los intentos de articular la propuesta freireana con la conceptualización de la 'práctica teórica' althusseriana con el malentendido estructural que acarrean los autores en torno al término práctica asociado con praxis (ver: Arrúa, 2017). Para los autores el Servicio Social debe superar la contradicción asistente/asistido en un proceso de superación y autoconsciencia en forma crítica y total. La diferencia entre el profesional y el asistido se basa en un "nivel diferente de percepción de la realidad". Las opciones, entonces, del profesional son el "cambio" o el "anti-cambio", el "dialogo" o el "anti-dialogo", en todo caso se presenta con claridad que el profesional no debe ser neutro frente al mundo. Esta crítica a la neutralidad no se vincula a una cuestión política sino a una cuestión instrumental, se trata de optar por el "cambio", con lo indeterminado de su significación concreta. Esto último determina su rol profesional con atributos tales como: "creer en el pueblo", "humildad", "capacidad de dialogo", "adherir a la praxis y no desideologizar".

En la formulación de los autores se insiste en el dialogo como principal aporte de Freire sin imponer temas o "necesidades nacidas de nuestra imaginación" (Kisnerman et alii, 1972, p. 11). El acento puesto en la no imposición de temas, ni marcos referenciales ni valorativos resulta contradictorio con la necesidad de una 'consciencia crítica' propuesta por Freire, que según los 
autores tiene que desminificar y/o decodificar la realidad y la conciencia mágica o ingenua. El acento está puesto en los temas generadores y el uso de un universo vocabular ligado a la comunidad regional que se aplica el método del diálogo. Resulta muy interesante observar que el término "concientización" o la "concepción bancaria de la educación" son apenas mencionados por los autores, mientras que la tarea parece ser la "humanización" del hombre, por más enigmático que suene.

En este sentido, en el número 18 (1972) de la revista Selecciones Gustavo Cirigliano, pedagogo, asiduo colaborador y socio intelectual de Aníbal Villaverde, con posiciones ideológicas católicas y nacionalistas, asesor del Ministerio de Educación durante el Onganíato, publica un texto titulado "Educación y concientización". Allí denuncia a la universidad de elitista y alienante respecto a las necesidades nacionales: "La universidad es la matriz del régimen establecido, a través de los diplomas y de las simulaciones académicas. Hay que destruir a ambos, ni más diplomas o títulos, ni más simulaciones académicas" (Cirigliano, 1972, p. 50). Asimismo, se apropia del término alienación para mostrar que la categoría de "desarrollo" y "subdesarrollo" son impuestas y alienantes a la búsqueda de una identidad nacional. El autor utiliza el término "concientización" para la "percepción autentica de los problemas argentinos", entre ellos la "dominación de Buenos Aires" al interior del país (Cirigliano, 1972, p. 52).

La posición de Kisnerman y Cirigliano comparten la búsqueda de un Freire atento a los problemas regionales y nacionales. En el primer caso, la propuesta del diálogo y la conciencia crítica y desmitificada en el Servicio Social aparece como una cuestión meramente instrumental, despojada de procesos de politización de las comunidades o los profesionales. El segundo realiza una operación ideológica que pretende emplazar a la propuesta freireana con las "necesidades nacionales" con la identificación de nudos tradicionales en el pensamiento nacionalista, tal como la dicotomía entre la "dominación porteña" versus "el interior sojuzgado". En ambas lecturas de Paulo Freire no se registran citas ni referencias al texto del pedagogo brasileño publicado por la revista Hoy sino las ediciones de sus libros en la editorial Tierra Nueva.

En el libro de Natalio Kisnerman Servicio Social Pueblo publicado en enero de 1972 por la editorial Humanitas desde una posición humanista despliega una dimensión metodológica del Servicio Social para pensar el Servicio Social despojada de la asunción de una posición política o crítica al rol de la profesión en la sociedad capitalista. El prólogo del libro manifiesta estar inspirado en el Congreso de Servicio Social en Teresópolis (Brasil) y le resta importancia a las diferencias terminológicas con que se conoce la profesión (asistencia social, servicio social, trabajo social), cuestión fundamental para el grupo ECRO. Incluso, en el capítulo "El proceso histórico del Servicio Social", el autor ni siquiera nombra al grupo o la revista, a diferencia de Hernán Kruse que coloca en un lugar central el rol de ECRO en el proceso de reconceptualización.

El autor presenta diversos instrumentos operativos para pensar el "objeto", el "sujeto", las metodologías de investigación y planificación de la intervención profesional. En cierto sentido, se retorna a una neutralidad política -que es una toma de posición- disimulada por el reconocimiento de problemáticas sociales en América Latina, tales como la 'marginalidad' que son también un posicionamiento ideológico respecto a los debates en torno a dicho concepto en las ciencias sociales. Las referencias a Freire se circunscriben a la enumeración de las diversas formas de conciencia (mágica, ingenua, fanática y crítica), donde la noción de "concientización" se reduce a la develación de la propia realidad de las causas históricas (Kisnerman, 1982, p. 70).

El libro fue duramente criticado por Ethel Cassineri y Ramon Vera en la revista Hoy en una extensa reseña bibliográfica inusual en la publicación que acostumbra situar la sección 
"Bibliográficas" al final de la revista con breves comentarios de libros. En este caso, la reseña aparece individualizada en el índice antes de la mencionada sección. Los autores califican al libro como "malo", ya que realiza una "mezcolanza" en un retorno a un "metodologismo aséptico", cuestión que criticaba el grupo ECRO de las conclusiones del Congreso de Teresópolis de 1971.

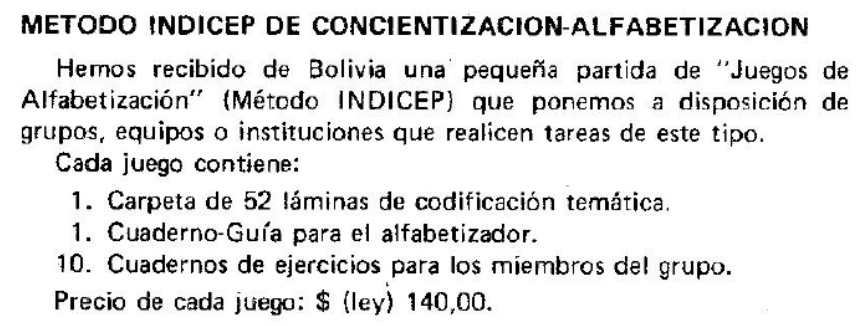

Los autores afirmaban que: "...una mezcla de Economía y Humanismo y CEPAL. Kisnerman le agrega Freire, pero hace un "pegote" [...] Le informamos a N.K. que los sistemas de graficación, comportan muchísimas cosas más que diagramas superficiales y cartogramas (pág. 170) como el afirma"' (Cassineri; Vera, 1973: 43-44). En la página final de la reseña aparece en la parte inferior una publicidad de venta de una partida de "Juegos de Alfabetización" del Método INDICEP realizado en Bolivia. La revista se muestra como interlocutor válido de las ideas freireanas y está dispuesta a batallar por ello.

Otra reseña del libro aparece en la revista Selecciones a cargo de Hernán Kruse. La misma es elogiosa respecto del libro de Kisnerman, Kruse afirmaba que Otra reseña del libro aparece en la revista Selecciones $(18,1972)$ a cargo de Hernán Kruse. La misma es elogiosa respecto del libro de Kisnerman, Kruse afirmaba que "Kisnerman nunca pierde de vista los aspectos políticos del servicio social y toma una clara posición al respecto". Según Siede, "Resulta importante destacar el comentario de Kruse no sólo por los elogios a la pretendida profundidad de la obra, sino por el fundamento que subyace en su última reflexión al equiparar una temática científica a la asepsia como regla, destacando en consecuencia, la excepción que configuraría la obra de Kisnerman" (Siede, 2015: 161). Se producen, entonces, dos lecturas contrapuestas del libro. Todos los involucrados son figuras destacadas del movimiento de reconceptualización, sin embargo, las diferencias emergen en la consideración metodológica de la profesión, la crítica a los "métodos básicos", las tensiones con la problemática de la "teoría propia", el proceso de politización y la alianza con el movimiento estudiantil para avanzar en las reformas curriculares.

\section{La disputa en imágenes}

La disputa por Freire como vimos había llegado a un punto álgido en los inicios de la década de 1970. La revista Hoy refleja esto en una caricatura de Juan Barreix de noviembre de 1971 que resulta importante por diversas razones: primero, porque da cuenta de una disputa en torno a la apropiación de las ideas de Freire en el Trabajo Social; segundo, que dicha disputa se 
combina con otra que tiene que ver con la crítica al "asistencialismo" que el grupo ECRO representa con una figura feminizada detrás de un escritorio.

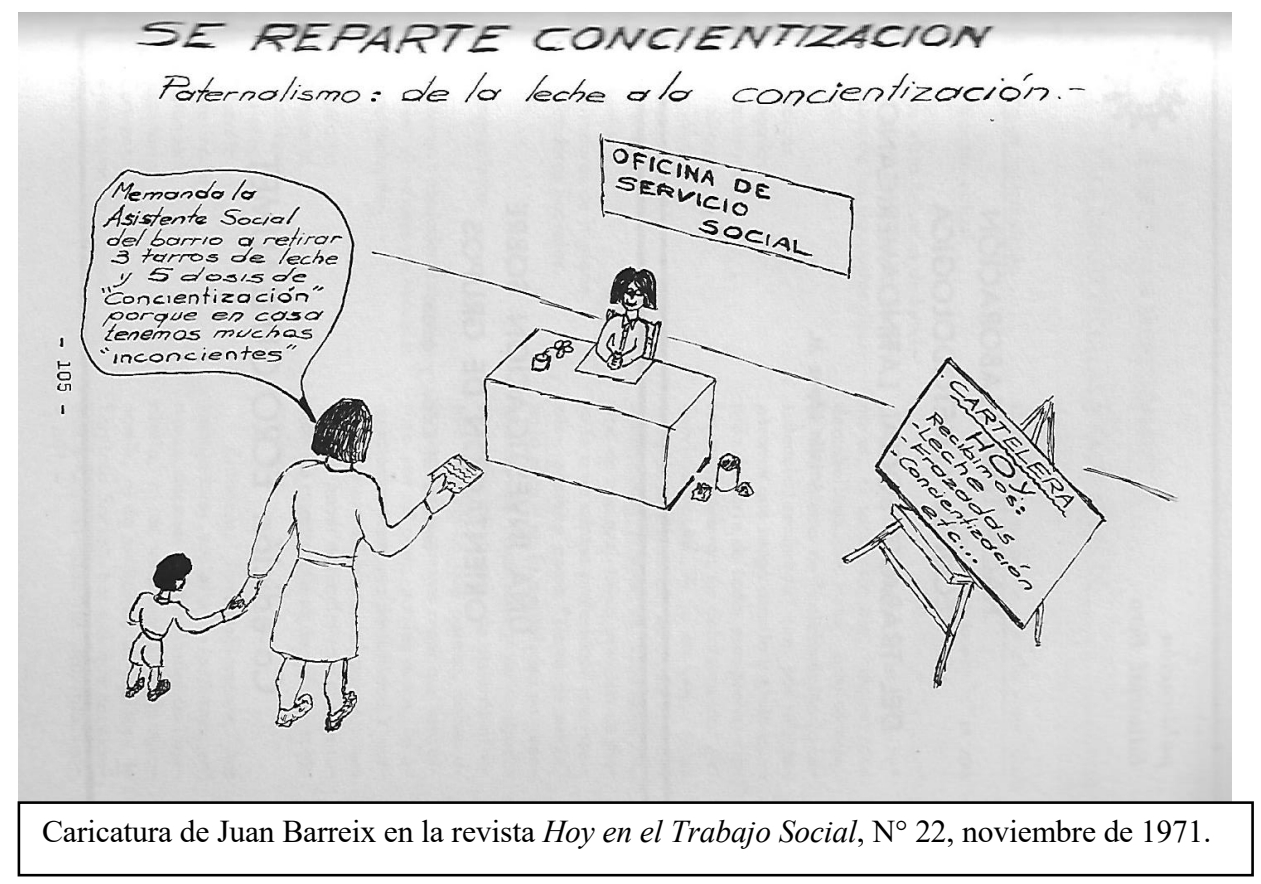

La posición de la profesional en la caricatura es pasiva y los usuarios se acercan enviados por otra profesional, por lo que, también da a entender de que no se trata de una cuestión episódica, sino que denuncia una vulgarización del término "concientización”, el cual aparece institucionalizado en los dispositivos ya existentes para mantener el "status quo". Resulta central que la mujer que se acerca a la oficina de Servicio Social afirme que la envía la "asistente social", no sólo se reproduce la feminización de la profesión y su asociación a las tendencias "tradicionales" de la profesión, sino que también alude a la terminología utilizada, cuestión para nada anodina para la revista Hoy. 


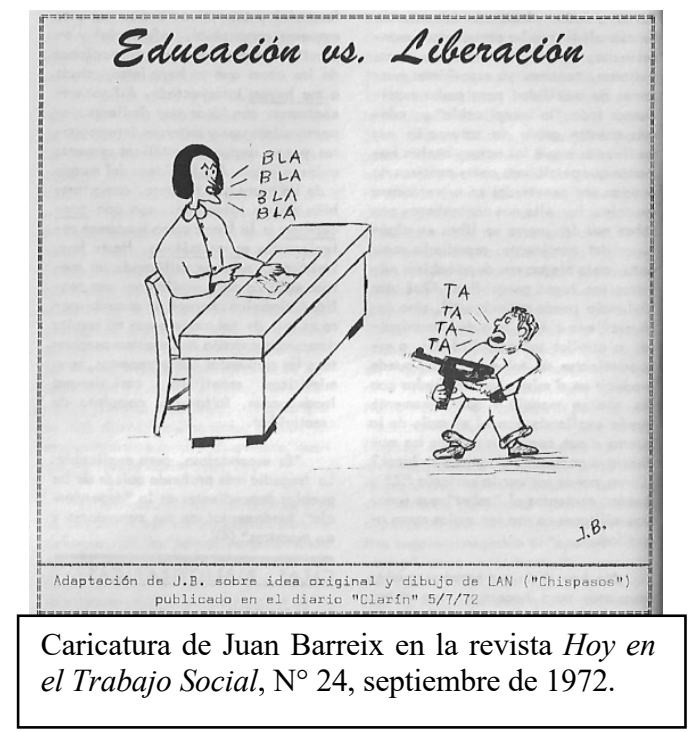

Esta intervención de Barreix se complementa con otra caricatura del número 24 (septiembre de 1972) que aparece nuevamente una profesional o educadora (nuevamente feminizada) detrás de un escritorio siendo "acribillada" por un niño en forma de juego que representa al "alumno" en clara actitud de insubordinación ante la autoridad a partir de la gestualidad del juego armado. La caricatura tiene el título de "Educacion vs. Liberación", en donde la opción se presenta entre la educación formal e institucional (la maestra detrás del escritorio) con un gesto de repetición o la lucha armada contra la autoridad establecida.

\section{Freire cuestionado}

El período entre abril de 1969 -cuando fue publicado por primera vez en Argentina un texto de Paulo Freire por el grupo ECRO- y fines de 1972 -cuando vuelve la revista Hoy a debatir las ideas de Paulo Freire- se caracteriza principalmente por la circulación masiva de los libros de Freire.

La circulación de los libros La Educación como práctica de la libertad, y Pedagogía del oprimido fue simultánea dado que fueron publicados por la editorial Tierra Nueva, en 1969 y 1970. Dicha editorial se encontraba en la constelación del pensamiento cristiano dirigida por Julio Barreiro junto con la prestigiosa revista Cristianismo y sociedad. La escasa capacidad de cubrir un mercado con una creciente demanda de los textos del pedagogo brasileño impulsó a la editorial a firmar convenio con el sello Siglo XXI, dirigido por el anteriormente mencionado Arnaldo Orfila Reynal (Brugaletta, 2017, pp. 31-36). A estos dos títulos se sumó en 1971 ¿Extensión o comunicación? Todos estos libros fueron previamente publicados por ICIRA en Chile, y contaron con la autorización de Freire para su edición en la Banda Oriental. 


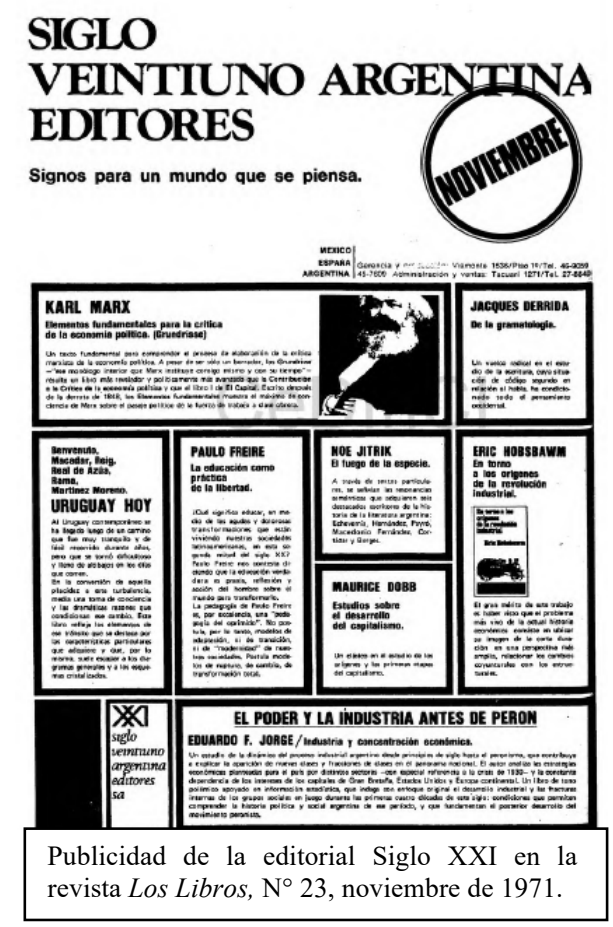

Ahora bien, la entrada de Paulo Freire a los catálogos de Siglo XXI implicaba compartir las listas de ventas y publicidades con autores de las ciencias sociales como Antonio Gramsci, Jacques Derrida, Eric J. Hobsbawm, Louis Althusser, Jacques Lacan o autores latinoamericanos como Pablo González Casanova, Armand Mattelart, Helio Jaguaribe, Eduardo Galeano. En el caso de Siglo XXI Argentina, la integración de José Aricó y el grupo intelectual de Pasado y Presente configuró un catálogo de autores de izquierdas heterodoxo con solidas posiciones en el mundo académico mediante la colección "Biblioteca del Pensamiento Socialista” (Sorá, 2017, p. 224).

Este auge de la edición y difusión de Freire determina su entrada a circuitos de lectura más amplios. El colectivo ECRO le dedica en diciembre de 1972 una crítica aguda al llamado "método Freire" en el número 25 de la revista Hoy. La editorial escrita por Barreix señala que se ha producido una mitificación en la profesión con el llamado "método de concientización" de Paulo Freire, dado que considera se ha fetichizado su pensamiento. Ahora bien, esta afirmación está precedida por el combate contra el "gatopardismo" y la falta de seriedad en las ciencias sociales, al tiempo que llama a "estudiar en serio". Por lo cual, podemos aseverar que la crítica a la fetichización de Freire tiene que ver con su vulgarización y masificación. Finalmente, Barreix se pregunta por qué las ideas de Freire antes "perseguidas" ahora son "consumidas" por el sistema: "...luego de un breve periodo de aparatosos y teatrales persecuciones hacia la persona de Freire y sus ideas pronto, muy pronto el sistema terminó asimilando con toda facilidad esas tan mentadas "técnicas psico-sociales de concientización"” (Barreix, 1972, p. 5). Incluso pone al pedagogo brasileño bajo sospecha al acusar de aceptar jugosos contratos en EE.UU. y como asesor del Consejo Mundial de Iglesias con sede en Ginebra.

La entusiasta introducción de Rodolfo Kusch en dicha sección de artículos le permitió a la revista tomar distancia de las tesis freireanas. Los nexos con Kusch, sin embargo, serán 
reafirmados en los números subsiguientes. El juego especular en el que Barreix y el colectivo ECRO se encontraban frente a la revista Selecciones del Servicio Social, tiene un episodio singular en las lecturas de Freire. Difundido e introducido como el intelectual más importante para el trabajo social en el año 1969 hacia 1972 se convertía en un representante del "sistema". Ejemplo valido de un escenario que se desplazaba hacia la izquierda en los debates de los profesionales radicalizados.

Este número tiene tres artículos sobre Freire: 1. "La concientización como praxis" de Elena Auad e Iris Tagle; 2. "Algunas consideraciones teóricas sobre el tema "la concientización y el trabajo social" de Humberto Castillo; 3. "Los preconceptos que suelen acompañar a las teorías desarrollistas (a propósito de Paulo Freire)" de Rodolfo Kusch.

Los dos primeros son relatos de experiencias de aplicación del método de alfabetización en Bolivia y Venezuela expuestas en el seminario internacional en Colombia organizado por el Instituto de Solidaridad Internacional de la Fundación Konrad Adenauer a fines del año 1971. Cabe recordar que en Bolivia durante dicho año aún gobernaba el militar afiliado a la izquierda, el General Juan José Torres. La experiencia venezolana fue apañada por el Instituto Agrario Nacional para la alfabetización de adultos en comunidades rurales. Ambas experiencias se refieren a la dinámica entre alfabetización y las comunidades agrarias en procesos de reforma y redistribución de la tierra. Ambas propuestas plantean límites y críticas al método Freire, en el primer caso, en el registro de reproducción de relaciones paternalistas en la relación con las comunidades, en el segundo caso, el autor se pregunta si es posible la liberación de un pequeño grupo en un marco de relaciones y estructuras que oprimen al hombre. Este señala que no hay concientizador ni concientizado, sino que la acción debe surgir de una disponibilidad común, un acto creador.

El artículo de Rodolfo Kusch aborda críticamente las ideas de Paulo Freire con el objetivo de situar al pedagogo brasileño en una saga de pensadores que intentan reproducir esquemas europeos y occidentales en la realidad latinoamericana. El autor sitúa a Freire en el desarrollismo, al plantear el carácter externo de la idea de desarrollo sobre las poblaciones campesinas y avasallar su cultura. Según Kusch, Freire "insiste en que hay que inculcar al campesino el ideal dinámico de la transformación de la naturaleza". La crítica al binarismo magia/ciencia y doxa/logos le permite a Kusch afirmar que Freire desconoce las estrategias y saberes campesinos al realizar un llamado a respetar las creencias y valores de los mismos. La oposición entre hombre y naturaleza, tanto como el concepto de la 'transformación de la naturaleza' cierran la posibilidad de comprender al mundo indígena, según el autor, al mismo tiempo que imponen una abstracción europea para entender la realidad latinoamericana.

La concepción fenomenológica del ser-ahí heideggeriano en Rodolfo Kusch se despliega en su crítica a Freire a partir de la cuestión de la 'autenticidad' del ser americano. En Kusch la cuestión de la autenticidad asume una crítica al eurocentrismo y la construcción de una metafísica que parte de una visión telúrica (la selva, la pampa). Según Ruvituso (2016):

El agudo análisis de Kusch de la soledad y angustia del hombre americano en la ciudad es una de las interpretaciones más originales de la filosofía existencialista en boga traspasada al hombre latinoamericano. Para Kusch, la ambivalencia y la angustia del americano se perciben en la manera de hacer historia, filosofía, política, en el sistema educativo y las leyes, producidos desde la ciudad desde una perspectiva foránea o ficcional. (257) 
La construcción de una américa mestiza yace en una dimensión subterránea anclada en el paisaje en la cual el indígena y el inmigrante podían encontrar puntos de encuentro. Esta visión telúrica implica un componente irracional en la formación de una consciencia americana.

El clivaje autenticidad/inautenticidad en la concepción del Ser forma parte de la corriente fenomenológica de la filosofía. El propio Paulo Freire era lector de Hegel y Husserl tal como puede evidenciarse en sus primeros textos y libros: el pedagogo concibe la autenticidad del Ser en relación a la liberación del sujeto de las ideas del opresor (Freire, 2014, p. 38). Por lo tanto, este proceso de toma de conciencia de su situación en el mundo o 'concientización', es un momento de reencuentro con su humanidad alienada. Por ello, consideramos que el pensamiento freireano es una variante historicista del proyecto moderno de emancipación del hombre.

En tanto Freire concibe al sujeto como el "hombre" -en términos genéricos- situado en una sociedad moderna bajo relaciones de opresión cultural y económica; en Kusch el sujeto es un ser-ahi telúrico, de una cultura trascendental americana. Ambos despliegan concepciones filosóficas fenomenológicas con conclusiones divergentes.

\section{Un desencuentro}

Con el retorno democrático en los inicios del año 1973 a partir del triunfo del peronista Héctor J. Cámpora en las elecciones, las distintas áreas del Estado fueron repartidas por las distintas tendencias del peronismo gobernante. El Ministerio de Cultura y Educación fue asumido por Jorge Taiana, y la Dirección de Nacional de Educación de Adultos (DINEA) por Carlos Grosso y Cayetano De Lella, por lo cual la tendencia revolucionaria del peronismo tenía un peso importante. Si bien la DINEA fue creada durante la dictadura de Onganía en 1968, los principios radicalizados de alfabetización y compromiso político desde una perspectiva freireana fueron desarrollados durante el tercer gobierno peronista. La creación del "método CREAR" para la alfabetización de adultos en Argentina partía de la identificación de una población de aproximadamente de tres millones de personas que no sabían leer ni escribir (Pérez Navarro; Tosolini, 2019, p. 117). El objetivo no sólo era erradicar el analfabetismo sino también promocionar la participación del pueblo en una estrecha vinculación de la educación con lo político (Rodríguez, 1996, p. 306). Para ello, se produce una adaptación en las palabras generadoras en sintonía con los propósitos señalados: se utilizan delegado, compañero, vecino, fútbol, pueblo organizado entre otras. Este método combinaba las ideas freireanas con los métodos de grupos del psicólogo social Enrique Pichón-Rivière (Pérez Navarro; Tosolini, 2019, p. 120). En este sentido, las lecturas de Freire de los integrantes que pusieron en marcha el "método CREAR" poseían una afinidad con la propuesta teórica del grupo ECRO en relación a las lecturas combinadas entre Pichón-Rivière y el pedagogo brasileño.

El propio Paulo Freire fue convocado por el Ministerio de Cultura y Educación de la Nación y la Universidad de Buenos Aires para brindar conferencias y asesoramiento al grupo a cargo de la educación de adultos en noviembre de 1973.

Esta visita fue registrada por la revista Selecciones, en una sección al final del número 21 (3er. Cuatrimestre de 1973) titulada "Freire estuvo en Argentina. Casi nadie pudo verlo", donde la publicación le dedica tres páginas a dicho acontecimiento. Con un tono amargo por no haber sido invitados a los seminarios y conferencias que brindó el pedagogo, el grupo editor de la revista informa a sus lectores sobre los ejes de la visita mediante una nota del diario La Opinión 
al mismo tiempo que dejaba en claro su "queja y frustración" por la ausencia de sus integrantes. El autor anónimo del texto refleja la posición de la revista alegando que hace cinco años las ideas de Freire circulaban en Argentina:

No fue la educación quién lo introdujo, fue el Servicio Social. Mucho antes de que llegara a las cátedras de Ciencias de la Educación, ya los estudiantes de Servicio Social y alguno que otro profesor, leían sus escritos en precarias impresiones mimeografiadas, cuyo origen no era fácil establecer. Las hojas a menudo borroneadas, conocidas "fichas" de los estudiantes, sin pie de imprenta y a veces por precaución hasta sin nombre del autor... pasaban de mano en mano ante la prohibición de las autoridades de alguna escuela que consideraban al autor "non sancto". (44)

Al tiempo que elude mencionar la publicación del texto de Freire por la revista Hoy reconoce al menos que textos del pedagogo circulaban en el Servicio Social en tiempos del onganiato. Si bien no contamos con materiales para dar cuenta de la trama material subterránea de textos y prácticas de edición y lecturas en tiempos de censura consideramos este fragmento como una indicación para futuras indagaciones en materia de estudios de la recepción de las ideas de este importante pedagogo.

Finalmente, este desencuentro del grupo que alienta la revista Selecciones con Paulo Freire no fue una cuestión anodina sino que demandó la necesidad de reafirmarse como verdaderos interlocutores de su pensamiento. ${ }^{3}$

\section{Coda}

Durante la "primavera camporista" las organizaciones estudiantiles, especialmente la Juventud Universitaria Peronista ligada a Montoneros convoca a los referentes del grupo ECRO para la intervención a las carreras de trabajo social de la UBA y Mendoza (Arrúa, 2019; Rubio, 2014). En plena efervescencia estudiantil, Juan Barreix fue recibido en Mendoza en un escenario convulsionado por las transformaciones políticas de la provincia gobernada por Alberto Martínez Baca considerada una "provincia montonera". En las notas que son publicadas por la revista siguiendo exhaustivamente los pasos de la intervención de Barreix aparece una fotografía de la puerta de la casa de estudios en la que se observan pintadas que aluden a las tesis freireanas y su lectura radicalizada: "No a la educación bancaria, Si a la liberadora"; "Por un trabajo social crítico y comprometido con el proyecto del pueblo: La patria socialista".

\footnotetext{
${ }^{3}$ Esta búsqueda de interlocución de las ideas freireanas en el campo intelectual del trabajo social llevó a la revista Selecciones en el número 19 (1er. Cuatrimestre de 1973) a publicar un artículo del trabajador social chileno Luis Araneda Alfero titulado "Concientización". Este ocupaba el cargo de presidente de la ALAESS (Asociación Latinoamericana de Escuelas de Servicio Social) y director de la carrera de Servicio Social de la Universidad de Concepción luego del breve interregno de Hernán Kruse. En el texto expone el concepto de conciencia y la propuesta freireana asociando la concientización a una "revolución cultural", una creación continua y una acción liberadora. Afirma que en Concepción (Chile) se lleva adelante la reforma curricular de la carrera de trabajo social con los principios de Freire, tales como Conciencia Crítica, Vocación de Transformación, que permiten la toma de conciencia. En septiembre de ese mismo año son intervenidas todas las universidades de Chile, y Araneda Alfero se exilia en Perú para trabajar en el Centro Latinoamericano de Trabajo Social en Lima (Perú) (Lamaisón; Celentano, 2019).
} 
Advertimos que la entrada de los referentes del grupo ECRO a la vida institucional y académica de las Escuelas de Servicio Social argentino adquiere un componente político radicalizado a partir de las posturas de la revista Hoy en su disputa con Selecciones.

En este acto de entrada de Barreix como interventor en Mendoza, las ideas de Freire generaron un encuentro entre el movimiento estudiantil y las posiciones intelectuales $\mathrm{y}$ profesionales del grupo ECRO.
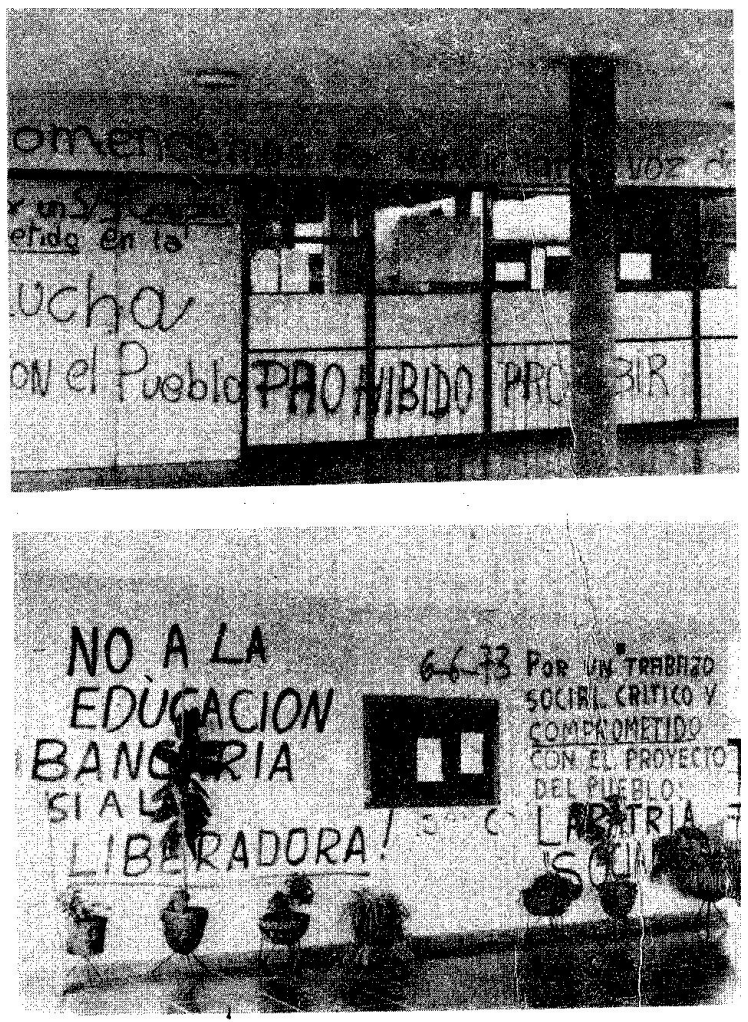

Las paredes de la Escuela de Servicio Social hiego de "la "toma" de la misma.

Imagen extraída de la revista Hoy en el Trabajo Social, $\mathrm{N}^{\circ} 27$, octubre de 1973, p. 83.

Las lecturas combinadas de Freire y Pichón-Rivière, la crítica a la vulgarización del término "concientización" y la necesidad de establecer diferencias con el "método" de Paulo Freire conjugaron una postura radicalizada en el Trabajo Social por parte del grupo ECRO. E incluso en la breve secuencia del gobierno de Campora el grupo que alienta la revista Hoy parecía haber logrado aquello que anhelaba tras el 4to. Seminario regional de Concepción: reformar los planes de estudio de las carreras en alianza con el movimiento estudiantil. Sin embargo, la propia dinámica de enfrentamientos y disputas intraperonistas durante el tercer gobierno peronista, al mismo tiempo que potenció las reformas curriculares y educativas, entre otras, también fue su límite a través de la 'misión Ivanissevich' del Ministerio de Cultura y Educación en 1974 y las intervenciones federales a las "provincias Montoneras" posteriormente (Franco, 2012, pp. 45-58). 


\section{Bibliografía}

Alayón, N. (1992) Historia del Trabajo Social en Argentina. Buenos Aires: Humanitas.

Alayón, N.; Barreix, J.; Cassineri, E. (1971) ABC del trabajo social latinoamericano. Buenos Aires: ECRO.

Althusser, L.; Baliar, E. (2010) Para leer El Capital. México: Siglo XXI.

Altamirano, C. (2013) Intelectuales. Notas de investigación sobre una tribu inquieta. Buenos Aires: Siglo XXI.

Anónimo (1971) Chile: la reforma universitaria en la Universidad de Concepción. Los Libros, 23, 14-20.

Araneda Alfero, L. (1973) Concientización. Selecciones de Servicio Social, 19, 3-13.

Aravena Alvarado, R.;Díaz-Diego, J. (2015) "Paulo Freire en chile (1964-1969): testimonios de exdirigentes campesinos durante la reforma agraria”. Dirección de Bibliotecas, Archivos y Museos. Informes de investigación 2015: Fondo de Apoyo a la Investigación Patrimonial.

Arrúa, N. (2017) La recepción intelectual de Louis Althusser entre los trabajadores sociales sudamericanos en los años setenta. En Rodríguez, M.; Starcenbaum, M. (eds.) Lecturas de Althusser en América Latina (261-288). Santiago de Chile: Doble Ciencia. (2019) Las carreras de Trabajo Social ante el retorno del peronismo, 1973-1974. Un análisis a partir del caso de Buenos Aires y La Plata. En Arbelo, H.; Acri, M.; Barbieri, C. (comps.) 1918: Un legado en disputa. La Reforma Universitaria en Argentina y Latinoamérica (139-160). Buenos Aires: Barcos Ediciones.

AA.VV. (1969) Nuevo intento de terrorismo ideológico. Suplemento especial de la revista Hoy en el Servicio Social 16-17. Buenos Aires: ECRO.

Barreix, J. (1972) Editorial. Hoy en el Trabajo Social, 25, 3-5.

Bauman, Z. (1997) Legisladores e intérpretes. Quilmes: UNQui.

Bourdieu, P. (2007) Intelectuales, politica y poder. Buenos Aires: Eudeba.

Brugaletta, F. (2017). El protestantismo y la circulación de la pedagogía de Paulo Freire en América Latina. Paulo Freire. Revista de Pedagogía Crítica, 17, 21-40.

Buchbinder, P. (2005) Historia de las universidades argentinas. Buenos Aires: Sudamericana.

Cassineri, E.; Vera, R. (1973) Lectura crítica de "Servicio Social-Pueblo". Hoy en el Trabajo Social, 26, 41-45.

Cavarozzi, M. (1997) Autoritarismo y democracia (1955-1996) La transición del Estado al mercado en la Argentina. Buenos Aires: Ariel, 1997.

Cirigliano, G. (1972) Educación y concientización. Selecciones de Servicio Social, 18, 48-52.

Dufour, A. (1969) El Servicio Social aprende a decir su palabra. Crónica del $4^{\circ}$ Seminario Regional Latinoamericano de Servicio Social. Hoy en el Servicio Social, 16-17, 51-70.

Dufour, A. (1969a) Editorial. Hoy en el Servicio Social, 16-17, 3-6.

Franco, M. (2012) Un enemigo para la nación. Orden interno, violencia y “subversión”, 1973 1976. Buenos Aires: FCE.

Freire, P. (1969) El rol del trabajador social en el proceso de cambio. Hoy en el Servicio Social, 16-17, 8-104. 
(2014) Pedagogía del oprimido. Buenos Aires: Siglo XXI.

González Monarde, S. (2019) Trayectoria de vida y redes intelectuales en Luis Vitale: Argentina, Chile y el exilio. Herramienta web, 26.

Gramsci, A. (1975) Los intelectuales y la organización de la cultura. México: Juan Pablos.

Illanes, M. A. (2009) Alicias ante el espejo. Trabajadoras sociales en busca de la participación. Chile en los sesenta. Nomadias, 9, 61-91.

Karsz, S. (2007) Problematizar el trabajo social. Definición, figuras, clínica. Barcelona: Gedisa. Kisnerman, N. (1982) Servicio Social Pueblo. Buenos Aires: Humanitas.

Kisnerman, N.; Malvino, M; Kisnerman, L.; Chirico, D. (1972) El proceso de concientización de Paulo Freire y su aplicación al Servicio Social. Selecciones de Servicio Social, 16, 5-20.

Lamaisón, M.J.: Celentano, A. (2019) Apuntes para una historia intelectual del trabajo social latinoamericano: los libros y las revistas del Centro Latinomericano de Trabajo Social (1975-1983). e-Latina, 66, 25-47.

Marchesi, A. (2019) Guerrillas latinoamericanas, de los años sesenta a la caída del Muro. Buenos Aires: Siglo XXI.

Moreau de Young, E. (1972) Ciencia social: nueva tarea histórica para el Trabajo Social. Selecciones de Servicio Social, 18, 5-9.

Moyano Barahona, C.; Loyoza, I. (2019) "Intelectuales de izquierda en Chile": ¿de la politización a la tecnocracia? Debates sobre la función política y el ser del intelectual entre 1960 y 1990. Signos Históricos, 41, 192-229.

O’Donnell, G. (1996) El Estado Burocrático Autoritario. Buenos Aires: Ed. Universidad de Belgrano.

Pécaut, D. (1990) Os intelectuais e a política no Brasil. Entre o povo e a nação. San Pablo: Ática.

Pérez Navarro, C.; Tosolini, M. Apropiaciones y adaptaciones de la pedagogía de Paulo Freire en las iniciativas de educación de adultos en Chile y Argentina (1965-1975). Anales de Historia de la Educación, vol. 20, 2, 111-128.

Portantiero, J.C. (1989) Economía y política en la crisis argentina (1958-1973). En Anzaldi, W.; Moreno, J.L. Estado y sociedad en el pensamiento nacional. Buenos Aires: Cántaro, 301-346.

Rodriguez, L. (2016) Paulo Freire. Una biografía intelectual. Buenos Aires: Colihue. (2003). "Pedagogía de la liberación y educación de adultos", en Puiggrós, A. Dictaduras y utopías en la historia reciente de la educación argentina (1955-1983). Buenos Aires: Editorial Galerna.

Rodríguez Rodríguez, M. (1971) La Rebelión Estudiantil y el Servicio Social. Hoy en el Trabajo Social, 21, 17-32.

Rubio, R. (2014) La alternativa de la "Comunidad Didáctica" en la reestructurada Escuela Superior de Servicio Social de Mendoza (1973-1974). En: Chávez, P.; Paredes, A.; Rodriguez Agüero, L. (comps.) Conflictos e identidades en la educación en Mendoza (1969-1973). Mendoza: Centro de Investigaciones FCPS.

Ruvituso, C. (2016) La recepción de Heidegger en la Argentina peronista (1946-1955). Cuatro casos contrapuestos. En Piovani, Juan; Ruvituso, Clara; Werz, Nikolaus (ed.) Transiciones, Memorias e Identidades en Europa y América Latina. Madrid: Iberoamericana/ Vervuert, 245-268.

Sarlo, B. (1992) Intelectuales y revistas: razones de una práctica. Cahiers du CRICCAL, 9-10, 916. 
Siede, M. V. (2015) Trabajo social, marxismo, cristianismo y peronismo: el debate profesional argentino en las décadas 60-70. La Plata: Dynamis.

Sorá, G. (2017) Editar desde la izquierda en América Latina. La agitada historia del Fondo de Cultura Económica y de Siglo XXI. Buenos Aires: Siglo XXI.

Tarcus, H. (2013) Marx en la Argentina. Sus primeros lectores obreros, intelectuales y científicos. Buenos Aires: Siglo XXI.

Terán, O. (2009) Historia de las ideas en la Argentina. Buenos Aires: Siglo XXI.

Tortti, M. C. (1999) Protesta social y nueva izquierda en la Argentina del Gran Acuerdo Nacional. En Pucciarelli, A. (ed.) La primacía de la política. Lanusse, Perón y la Nueva Izquierda en tiempos del GAN. Buenos Aires: Eudeba.

Tortti, M.C.; Celentano, A.; Chama, M. (2014) (coords.) La nueva izquierda argentina (19551976). Socialismo, peronismo y revolución. Rosario: Prohistoria.

Traverso, E. (2014) ¿Qué fue de los intelectuales? Buenos Aires: Siglo XXI. 